Borja Gonzalez Prieto, Alessandro Marino, Jun Lim, Kris Rosseel, Johan Martens, Matthias Rizzi, Jörg Neuhausen, Joris Van den Bosch, and Alexander Aerts*

\title{
Use of the transpiration method to study polonium evaporation from liquid lead-bismuth eutectic at high temperature
}

\begin{abstract}
Qualitative and quantitative understanding of Po volatilization under different conditions is of key importance for safety assessments of lead-bismuth eutectic (LBE) based nuclear reactors, spallation targets and accelerator driven systems. In this work we explore the possibilities of the transpiration method in combination with simple models to study the equilibrium and kinetics of Po evaporation from highly diluted solutions in lead-bismuth eutectic between 600 and $1000{ }^{\circ} \mathrm{C}$ in $\mathrm{Ar} / 5 \% \mathrm{H}_{2}$ and Ar. On the basis of evaporation experiments at various carrier gas flow rates, we identified the conditions of vapor saturation allowing the determination of equilibrium constants. From the limiting behavior at high flow rates, values for the maximal evaporation rate of Po from LBE were estimated. Measurements of evaporation as a function of time were consistent with the assumption that polonium dissolved in LBE obeys Henry's law. A theoretical analysis furthermore suggested that diffusion of polonium in LBE was not a rate limiting factor for evaporation under vapor saturation conditions. Newly determined values for the Henry constant of Po in LBE between 600 and $1000^{\circ} \mathrm{C}$ were consistent with previously derived correlations.
\end{abstract}

Keywords: Lead-bismuth eutectic, Polonium, Transpiration method, Evaporation, Henry constant, Alloy.

\footnotetext{
*Corresponding author: Alexander Aerts, SCKCEN (Belgian Nuclear Research Centre), Boeretang 200, 2400 Mol, Belgium, e-mail: aaertsl@sckcen.be
}

Borja Gonzalez Prieto: SCKCEN (Belgian Nuclear Research Centre), Boeretang 200, $2400 \mathrm{Mol}$, Belgium; and Centre of Surface Chemistry and Catalysis, KU Leuven, Kasteelpark Arenberg 23, 3001 Heverlee, Belgium

Alessandro Marino: SCKCEN (Belgian Nuclear Research Centre), Boeretang 200, $2400 \mathrm{Mol}$, Belgium; and Vrije Universiteit Brussel, Pleinlaan 2, 1050 Elsene, Belgium

Jun Lim, Kris Rosseel, Joris Van den Bosch: SCKCEN (Belgian Nuclear Research Centre), Boeretang 200, $2400 \mathrm{Mol}$, Belgium Johan Martens: Centre of Surface Chemistry and Catalysis, KU Leuven, Kasteelpark Arenberg 23, 3001 Heverlee, Belgium Matthias Rizzi, Jörg Neuhausen: Laboratory for Radio- and Environmental Chemistry, Paul Scherrer Institute, Villigen PSI, CH5232 Villigen
DOI 10.1515/ract-2014-2263

Received February 27, 2014; accepted June 11, 2014

\section{Introduction}

Disposal of high-level radioactive waste in deep geological layers and repositories has been widely investigated during the past decades with on-going projects in countries such as Sweden [1, 2] and Belgium [3]. However, the time scale needed for the radiotoxicity of the waste to drop to the level of natural uranium is very long (i.e., of the order of 500000 to 1 million years) [4]. A possible solution to significantly reduce this time scale emerges from the transmutation of high-level radioactive elements with long half-life, such as minor actinides. To this aim, nuclear reactors with a fast spectrum and accelerator-driven systems (ADS) are considered a suitable solution. The first research ADS, MYRRHA (Multi-purpose hYbrid Research Reactor for High-tech Applications), is currently under development at SCK-CEN (Belgium) $[4,5]$ and consists of a subcritical core coupled to a proton accelerator. In this system, liquid lead-bismuth eutectic (LBE) serves as both spallation target and coolant.

LBE (44.5 wt. \% Pb; 55.5 wt. \% Bi) combines favorable physicochemical properties for its use in the safe operation of this sort of installations [6]. However, during operation of these facilities, several hazardous radionuclides such as Po and $\mathrm{Hg}$ isotopes are formed by neutron activation and spallation reactions. Therefore a good understanding and accurate quantitative data of the evaporation of these radionuclides from LBE are essential to assess the radiological impact during normal operation and accident scenarios of nuclear facilities. In support of the MYRRHA ADS project, the physicochemical behavior of traces of polonium and mercury dissolved in liquid metals is currently being studied by experiment [7-10] and density functional theory methods [11].

The study of the evaporation behavior of polonium is of particular interest. Polonium-210 is a pure $\alpha$-emitter and is formed in significant amounts especially in heavy 
metal coolant containing bismuth, such as LBE. The socalled transpiration method has been most frequently used to study Po evaporation from LBE $[6-8,10,12,13]$. Recently [7], we proposed a simple model that allows the derivation of Henry's law constants for Po dissolved in LBE from experimental data obtained by the transpiration method at high temperature $\left(600-1000^{\circ} \mathrm{C}\right)$. The validity of the model was supported by concurrent reference measurements of the vapor pressure of LBE.

In the present paper we investigate several of the assumptions of this transpiration method model in more detail by performing dedicated experiments with pure LBE as well as with Po dissolved in LBE.

First, it is an assumption of the model that thermodynamic equilibrium between the dissolved element, polonium in the present case, and its vapor is closely approached. In practice this condition implies that the carrier gas becomes saturated with vapors when flowing over the sample.

Secondly, it is required that the vapors are predominantly transported by advection [14-16]. The conditions where saturation and advective transport prevail are identified in the same type of experiment, i.e. by measuring evaporation at different flow rates of the carrier gas. In the present contribution we show the results of such a flow rate-dependent experiment for LBE and Po dissolved in LBE.

A third assumption is that the equilibrium between dissolved polonium and its vapor follows Henry's law. One of the consequences of this is that the rate of Po evaporation is proportional to its concentration in the liquid metal solvent. We verified this condition by measuring time-dependent evaporation. A simulation was performed to evaluate diffusion transport limitations of Po in liquid LBE during such evaporation experiments.

With these dedicated experiments, together with additional measurements of the Henry constants for Po(lbe) at different temperatures in $\mathrm{Ar} / 5 \% \mathrm{H}_{2}$, we show that between 600 and $1000{ }^{\circ} \mathrm{C}$ Po evaporation closely follows the behavior predicted by the transpiration model and a single correlation for the Henry constant.

\section{Theoretical models and data analysis}

We start by summarizing the model for evaporation of pure LBE [7] since we use this system as a reference for our experiments with Po. When LBE vapor - which is thought to consist of $\mathrm{Pb}(\mathrm{g}), \mathrm{Bi}(\mathrm{g})$ and $\mathrm{Bi}_{2}(\mathrm{~g})$ molecules [17] - is at equilibrium with the LBE melt and is transported by advection, the weight loss of the LBE sample during a transpiration experiment is given by:

$$
\begin{aligned}
\Delta m_{\mathrm{lbe}} & =m_{\mathrm{lbe}}(0)-m_{\mathrm{lbe}}(t) \\
& =\frac{\dot{V} t}{R T_{0}}\left(M_{\mathrm{Pb}(\mathrm{g})} p_{\mathrm{Pb}(\mathrm{g})}+M_{\mathrm{Bi}(\mathrm{g})} p_{\mathrm{Bi}(\mathrm{g})}+M_{\mathrm{Bi}_{2}(\mathrm{~g})} p_{\mathrm{Bi}_{2}(\mathrm{~g})}\right)
\end{aligned}
$$

where $t$ is the experiment time $[\mathrm{s}], \dot{V}$ is the carrier gas flow rate $\left[\mathrm{m}^{3} \mathrm{~s}^{-1}\right], R$ is the ideal gas constant $\left[8.31 \mathrm{~J} \mathrm{~mol}^{-1} \mathrm{~K}^{-1}\right]$ and $T_{0}=273.15 \mathrm{~K}$. The factors $M$ and $p$ are, respectively, the molecular weights $\left[\mathrm{g} \mathrm{mol}^{-1}\right]$ and equilibrium partial pressures $[\mathrm{Pa}]$ of the vapor species.

If we define the average molecular weight of the vapor above LBE as:

$$
\overline{M_{\mathrm{lbe}(\mathrm{g})}}=\frac{\sum_{i} M_{i} p_{i}}{\sum_{i} p_{i}}=\frac{\sum_{i} M_{i} p_{i}}{p_{\mathrm{lbe}(\mathrm{g})}}
$$

then:

$$
\Delta m_{\mathrm{lbe}}=\frac{\dot{V} \overline{M_{\mathrm{lbe}(\mathrm{g})}} p_{\mathrm{lbe}(\mathrm{g})}}{R T_{0}} t
$$

A correlation for the temperature dependence of the average molecular weight of the vapor at equilibrium above LBE and its derivation are presented as supplementary information.

For the evaporation of polonium from LBE, a model was proposed [7] which, under the conditions outlined in the introduction, results in the following first-order expression for the fractional release of Po from LBE:

$$
\frac{n_{\text {Po(lbe) }}(0)-n_{\text {Po(lbe) }}(t)}{n_{\text {Po(lbe) }}(0)}=1-\exp \left[-\frac{K_{\text {Po(lbe) }} M_{\text {lbe }} \dot{V}}{m_{\text {lbe }}(0) R T_{0}}\right]
$$

where $n_{\mathrm{Po}(\mathrm{lbe})}$ is the molar amount of Po dissolved in LBE, $m_{\mathrm{lbe}}(0)$ is the initial mass of LBE sample [g], $M_{\mathrm{lbe}}$ is the molecular weight of LBE [208.2 $\left.\mathrm{g} \mathrm{mol}^{-1}\right]$ and $K_{\mathrm{Po}(\mathrm{lbe})}$ is the Henry constant defined as:

$$
\begin{aligned}
p_{\text {Po }} & =K_{\mathrm{Po}(\mathrm{lbe})} x_{\mathrm{Po}(\mathrm{lbe})} \\
& =K_{\mathrm{Po}(\mathrm{lbe})} \frac{n_{\mathrm{Po}(\mathrm{lbe})} M_{\mathrm{lbe}}}{m_{\mathrm{lbe}}}
\end{aligned}
$$

where $p_{\text {Po }}$ is the partial pressure of (monoatomic) Po species $[\mathrm{Pa}]$ and $x_{\mathrm{Po}(\mathrm{lbe})}$ is the mole fraction of Po dissolved in LBE.

A refined model considering the influence of solvent (LBE) evaporation on the Po concentration was derived 
as well. However, the LBE evaporation data [7] revealed that the relative mass loss of the LBE sample was limited (3\%), even during experiments at a maximal temperature of $1000{ }^{\circ} \mathrm{C}$. Therefore in the present work we further use the simpler model of Equation (4).

\section{Experimental}

LBE cylinders of $5 \mathrm{~mm}$ diameter and $13 \mathrm{~mm}$ height with a mass of $c a .2 .7 \mathrm{~g}$ and Po mole fraction between $10^{-12}$ and $10^{-10}$ were used in the evaporation experiments. The samples were produced by neutron irradiation of LBE in the BR1 reactor at SCK-CEN.

The transpiration set-up for evaporation experiments consists of three main parts: a gas supply section, an evaporation section consisting of a quartz tube heated by a tube furnace, and finally, an exhaust section containing filters for gas cleaning and contamination monitoring. The setup is described in detail in Ref. [7]. Samples were loaded in the $1 \mathrm{~cm}$ diameter quartz tube either in a quartz sample boat or on a small piece of Mo foil. Before evaporation experiments, ${ }^{210}$ Po-doped LBE samples were pretreated at $600{ }^{\circ} \mathrm{C}$ in $\mathrm{Ar} / 5 \% \mathrm{H}_{2}$ for $30 \mathrm{~min}$ to reduce oxides.

Evaporation experiments (either in $\mathrm{Ar} / 5 \% \mathrm{H}_{2}$ or $\mathrm{Ar}$ ) above $650{ }^{\circ} \mathrm{C}$ were performed following the procedure described in Ref. [7]. Here the amount of evaporated polonium was quantified by comparing measurements of the polonium activity in the LBE sample before and after the experiment. For evaporation experiments below $650{ }^{\circ} \mathrm{C}$ another procedure was used. At those temperatures the release of Po during the experiment is too low $(<0.2 \%$ of the total Po in the sample) to be quantified by differential measurement of the polonium concentration in the sample. In this case the amount of evaporated Po was determined by quantitatively collecting the Po vapors that had condensed on the quartz tube walls and subsequent activity measurement. The procedure was based on that described in Ref. [8]. To dissolve condensed Po from the quartz wall, the tube was rinsed with $7 \mathrm{M} \mathrm{HNO}_{3}$. Two rinses of $3 \mathrm{ml}$ were found to be sufficient for quantitative dissolution. The $\alpha$ activity and thus the amount of evaporated polonium of the rinsing solutions was subsequently determined by liquid scintillation counting.

In this work we measured Po evaporation as function of gas flow rate, time and temperature. Po evaporation at different flow rates of $\mathrm{Ar} / 5 \% \mathrm{H}_{2}$ carrier gas $(20-300 \mathrm{~mL} / \mathrm{min}$ at STP) at constant temperatures of 600 and $1000{ }^{\circ} \mathrm{C}$ was measured in one-hour experiments. Time-dependent experiments were performed at a constant flow of $100 \mathrm{~mL} / \mathrm{min}$ at STP of either Ar or $\mathrm{Ar} / 5 \% \mathrm{H}_{2}$ and constant temperature of either 600 or $1000{ }^{\circ} \mathrm{C}$. The evaporation was interrupted at different experiment times between $2 \mathrm{~min}$ and $1 \mathrm{~h}$ and the amount of polonium evaporated was determined after each step. Finally, for temperature-dependent evaporation experiments between 600 and $1000{ }^{\circ} \mathrm{C}$, a constant flow rate of $100 \mathrm{~mL} / \mathrm{min} \mathrm{STP} \mathrm{Ar} / 5 \% \mathrm{H}_{2}$ and a duration of $1 \mathrm{~h}$ were chosen.
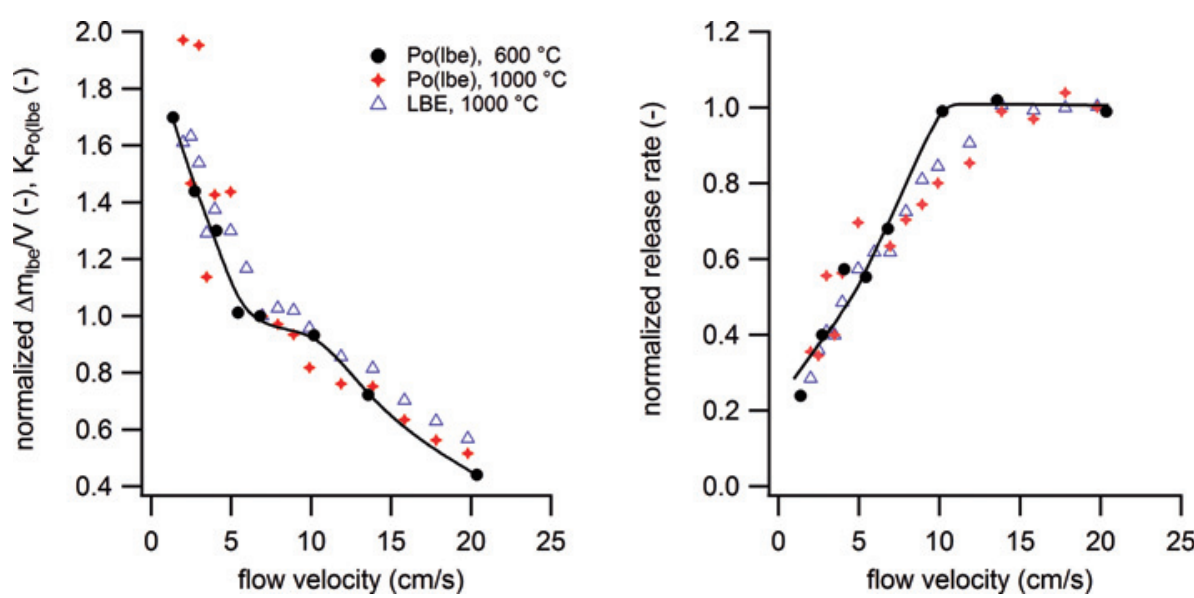

Fig. 1: (left) Normalized weight loss per unit volume carrier gas of LBE at $1000^{\circ} \mathrm{C}$ and normalized Henry constant of Po(lbe) at $600{ }^{\circ} \mathrm{C}$ and $1000^{\circ} \mathrm{C}$ as function of carrier gas flow velocity. (right) Corresponding normalized evaporation rates of LBE and Po(lbe). Curves through the $\mathrm{Po}$ (lbe) data at $600{ }^{\circ} \mathrm{C}$ serve as a guide to the eye. Errors on the Po data at $1000^{\circ} \mathrm{C}$ and $600{ }^{\circ} \mathrm{C}$ are approximately $10 \%$ and $1 \%$, respectively. 


\section{Results and discussion}

\subsection{Polonium evaporation at different carrier gas flow rates}

The saturation of the carrier gas with Po or LBE vapors and the vapor transport mechanism were investigated by transpiration experiments at different flow rates. Three data sets were measured: $\mathrm{Po}(\mathrm{lbe})$ at 600 and $1000{ }^{\circ} \mathrm{C}$ and pure LBE at $1000{ }^{\circ} \mathrm{C}$ (Figure 1a). These values were the set temperatures of the furnace. The measured temperatures at ca. $1 \mathrm{~mm}$ from the sample surface were 598 and $982^{\circ} \mathrm{C}$, respectively. In the remainder of the paper we will refer to the set temperatures. Weight losses per unit volume carrier gas $V=\dot{V} t$ at different flow rates (for LBE) and Henry constants (for Po dissolved in LBE) were calculated according to Equations (3) and (4), respectively. These data were normalized to their respective values at $100 \mathrm{~mL} / \mathrm{min}$ (at standard $T$ and $p$ ), to facilitate comparison between different data sets. Normalization factors were $\Delta m_{\mathrm{lbe}} / V=$ $15.5 \mathrm{~g} \mathrm{~m}^{-3}$ for LBE at $1000{ }^{\circ} \mathrm{C}$, and $K_{\mathrm{Po}(\mathrm{lbe})}=7.2 \mathrm{~Pa}$ and $6684 \mathrm{~Pa}$ for Po(lbe) at 600 and $1000^{\circ} \mathrm{C}$ respectively. In Figure 1a the normalized data are plotted $v s$. the actual carrier gas flow velocities at the experimental temperature rather than vs. volumetric flow rate at standard conditions. This way of representing the data allowed better comparison of the evaporation experiments at different temperatures. Values of the gas flow velocity were calculated applying temperature-dependent conversion factors to the actual volumetric flow rate. These conversion factors were 15 and

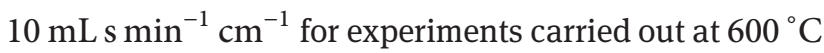
and $1000^{\circ} \mathrm{C}$, respectively.

The overall trend of the data for LBE and for Po(lbe) at both temperatures was similar and corresponded to the typical flow velocity (or flow rate) dependence observed in transpiration studies [15, 16, 18].

Data of the Po(lbe) sample at $600{ }^{\circ} \mathrm{C}$ showed a nearly constant region at intermediate flow velocities viz. $5-10 \mathrm{~cm} / \mathrm{s}$, corresponding to a flow rate of $75-150 \mathrm{~mL} / \mathrm{min}$ at STP. This constant region indicates saturation of the carrier gas with Po vapors and their transport by advection. At flow rates below the constant region, transport becomes controlled by diffusion of vapors in the carrier gas instead of advection, leading to overestimated values of the Henry constant or vapor pressure when calculated by the models outlined in section 2. At flow rates above the constant region, the carrier gas ceases to be saturated leading to underestimation of values. A clear constant region was not observed for experiments performed at $1000^{\circ} \mathrm{C}$ both for Po(lbe) and
Table 1: Henry constants, maximal evaporation rates and vaporization coefficients derived from the experiments at different flow rates.

\begin{tabular}{lrlrr}
\hline & LBE & & Po(lbe) & Po(lbe) \\
\hline$T_{\text {set }}\left({ }^{\circ} \mathrm{C}\right)$ & 1000 & & 600 & 1000 \\
$T_{\text {meas }}\left({ }^{\circ} \mathrm{C}\right)$ & 982 & & 598 & 982 \\
$p_{\text {lbe }(\mathrm{g})}(\mathrm{Pa})$ & 174 & $K_{\text {Po(lbe) }}(\mathrm{Pa})$ & 7.2 & 6684 \\
Evaporation rate & $1.8 \times 10^{-3}$ & Rate constant & $1.0 \times 10^{-2}$ & 8.8 \\
$\left(\right.$ mol m $\left.^{-2} \mathrm{~s}^{-1}\right)$ & & $\left(\mathrm{m}^{-2} \mathrm{~s}^{-1}\right)$ & & \\
$\alpha_{\text {lbe }}$ & $1.3 \times 10^{-3}$ & $\alpha_{\text {Po(lbe) }}$ & $1.4 \times 10^{-3}$ & $1.5 \times 10^{-3}$ \\
\hline
\end{tabular}

LBE. However a change of slope at gas velocities between $5-10 \mathrm{~cm} / \mathrm{s}$ indicated the transition from saturation and diffusive transport to undersaturation.

At high flow velocities the trends for LBE at $1000{ }^{\circ} \mathrm{C}$ and for Po(lbe) at 600 and $1000{ }^{\circ} \mathrm{C}$ were similar. This suggested that the causes for undersaturation (incomplete mixing, insufficiently rapid evaporation [15]) were not strongly dependent on temperature nor on the nature of the evaporating species. Also at low flow velocities in the vapor diffusion controlled regime the difference between the three data sets was small. We inferred from the trend of the flow rate dependence curves that data between $5-10 \mathrm{~cm} / \mathrm{s}$ should be near to equilibrium values. Experiments described further in this work were performed at a carrier gas flow rate of $100 \mathrm{~mL} / \mathrm{min}$ STP, which falls in the $5-10 \mathrm{~cm} / \mathrm{s}$ range where equilibrium prevails.

In addition to the determination of equilibrium quantities (vapor pressure and Henry constants), the experiments with variation of flow rate also allowed to estimate dynamical properties of the evaporation process. A plot of the release rates, rather than the vapor pressure or Henry constant, vs. carrier gas flow velocity revealed a constant region above $10 \mathrm{~cm} / \mathrm{s}$ for Po(lbe) at $600{ }^{\circ} \mathrm{C}$ and $14 \mathrm{~cm} / \mathrm{s}$ for experiments with both Po(lbe) and LBE at $1000{ }^{\circ} \mathrm{C}$ (Figure $1 \mathrm{~b}$ ). We attribute this region to the so-called vaporization limit [19], where the evaporation rate from the surface is maximal. The release rates for LBE were calculated from the factor between brackets in Equation (1) and that of Po(lbe) by the exponential rate constant in Equation (4). Experimental values for the maximal evaporation rates of LBE and Po from LBE are listed in Table 1. These values are useful for the conservative evaluation of polonium release rate from LBE, which is especially important in studies of accident scenarios of LBE-based nuclear installations.

The experimental values for the maximal evaporation rate were further interpreted in terms of the Hertz-Knudsen equation [20]. This equation describes the relation between the evaporation rate and the vapor pressure. For the 
molar evaporation rate of LBE, we define the expression:

$$
\left[\frac{\mathrm{d} n_{\mathrm{lbe}}}{\mathrm{d} t}\right]_{\max }=\frac{1}{\overline{M_{\mathrm{lbe}(\mathrm{g})}}}\left[\frac{\mathrm{d} m_{\mathrm{lbe}}}{\mathrm{d} t}\right]_{\max }=\alpha_{\mathrm{lbe}} A \sum_{i} \frac{p_{i}}{\sqrt{2 \pi M_{i} R T}}
$$

with the properties of vapor species $i$ as defined in Equation (1). For the evaporation rate constant of dissolved Po in LBE, with the assumption of Henry's law (Equation 5), one gets:

$$
\begin{aligned}
{\left[\frac{1}{n_{\mathrm{Po}(\mathrm{lbe})}} \frac{\mathrm{d} n_{\mathrm{Po}(\mathrm{lbe})}}{\mathrm{d} t}\right]_{\max } } & =\left[\frac{\ln \left(n_{\mathrm{Po}(\mathrm{lbe})} / n_{\mathrm{Po}(\mathrm{lbe})}(0)\right)}{t}\right]_{\max } \\
& =\alpha_{\mathrm{Po}(\mathrm{lbe})} A \frac{K_{\mathrm{Po}(\mathrm{lbe})}}{n_{\mathrm{lbe}} \sqrt{2 \pi M_{\mathrm{Po}} c R T_{0}}}
\end{aligned}
$$

In these equations the maximal rates (left-hand sides) were estimated by averaging the 3-4 data points at the highest flow velocities (Figure 1b). $A$ is the evaporation surface of the LBE sample which was estimated to be $6 \times 10^{-5} \mathrm{~m}^{2}$. The factors $\alpha$ [-] are so-called vaporization coefficients. From an evaluation of the right-hand side of the equations, the vaporization coefficients were derived. The factors $M_{i}$ and $p_{i}$ in the equation for LBE were evaluated following the procedure outlined in our previous work [7]. The right hand side of Equation (7) was evaluated with $K_{\text {Po(lbe) }}=7.2 \mathrm{~Pa}$ and $6684 \mathrm{~Pa}$ for $600^{\circ} \mathrm{C}$ and $1000^{\circ} \mathrm{C}$, respectively. Gaseous polonium was assumed to be elemental Po(g) so $M_{\text {Po }}=210 \mathrm{~g} / \mathrm{mol}$.

Theoretically vaporization coefficients are equal to 1 for evaporation from a clean surface into vacuum and if the primary evaporation products correspond to the equilibrium species [21, 22]. The latter was found to be the case for practically all pure metals [22], indicating that also for a binary alloy such as LBE the vaporization coefficient should be 1 theoretically.

Calculated vaporization coefficients as defined in Equations (6) and (7) are listed in Table 1. Vaporization coefficients of LBE at $1000^{\circ} \mathrm{C}$ and Po(lbe) at 600 and $1000{ }^{\circ} \mathrm{C}$ were almost identical. Values were three orders of magnitude smaller than the theoretical value of 1 in vacuum (Table 1). Previous measurements of the vaporization coefficients of $\mathrm{Pb}, \mathrm{Li}$ [23] and $\mathrm{Po}$ [24] from PbLi eutectic showed similar differences between experiments performed in 1 bar of He or Ar and experiments in vacuum. By analogy, we attribute the reduction of the vaporization coefficient for LBE and Po mainly to the presence of a carrier gas at $c a$. 1 bar. Hindered evaporation due to an oxide layer floating on top of the LBE seemed not likely. The surface of LBE samples during experiments was clean and had a metallic lustre, as indicated by visual inspection. This was not surprising because thick oxide layers are not expected to form under the present experimental conditions: at high temperature, oxygen solubility in LBE is high [25] and the hydrogen in the carrier gas produces a reducing atmosphere.

\subsection{Time-evolution of polonium evaporation}

To further verify the transpiration model, the release of LBE and Po was determined as function of time. Equations (3) and (4) predict release curves as function of time for LBE and Po(lbe) respectively. The first-order release of the $\mathrm{Po}(\mathrm{lbe})$ is a consequence of the assumed uniform depletion of Po in the sample. At elevated temperatures the release curve is exponential. However, at low fractional release occurring at low evaporation temperature, there is no significant Po depletion and a linear release curve is obtained.

The experimental results clearly conformed to the model predictions, as demonstrated by the correspondence of data and model fits in Figure 2. The weight loss of $\operatorname{LBE}\left(\Delta m_{\mathrm{lbe}}\right)$ at $1000^{\circ} \mathrm{C}$ (Figure 2a) and the fractional Po release from LBE at $600{ }^{\circ} \mathrm{C}$ were approximately linear (Figure 2b), whereas at $1000^{\circ} \mathrm{C}$ Po release was exponential (Figure 2c).

Recently it was found that at temperatures below $600^{\circ} \mathrm{C}$, deviations from this model behavior occur $[8,10]$. At low temperatures, release was fast initially and then regressed to linear model-type behavior [10]. The fast initial release was tentatively attributed to polonium evaporating from a surface layer of lead and bismuth oxides [10]. As already mentioned, in the present work samples at temperatures between 600 and $1000{ }^{\circ} \mathrm{C}$ did not show any (visual) sign of oxide layers, which seems to be consistent with the absence of an initially released polonium fraction.

Besides these experiments in reducing atmosphere $\left(\mathrm{Ar} / 5 \% \mathrm{H}_{2}\right)$, time-dependent evaporation experiments at 600 and $1000{ }^{\circ} \mathrm{C}$ were also performed in pure argon. The results in both atmospheres were identical within experimental error. Thus at these temperatures, the presence of hydrogen in the cover gas appears to have no influence on Po evaporation. This result could be again explained by the high oxygen solubility at 600 and $1000{ }^{\circ} \mathrm{C}(0.005$ and $0.2 \mathrm{wt}$. \%, respectively, according to the correlation of Ref. [25]) which results in the absence of oxide layers even in atmosphere without hydrogen. This result also indicates that volatile Po species such as $\mathrm{H}_{2}$ Po were not formed in the presence of a few percent hydrogen in the carrier gas. 

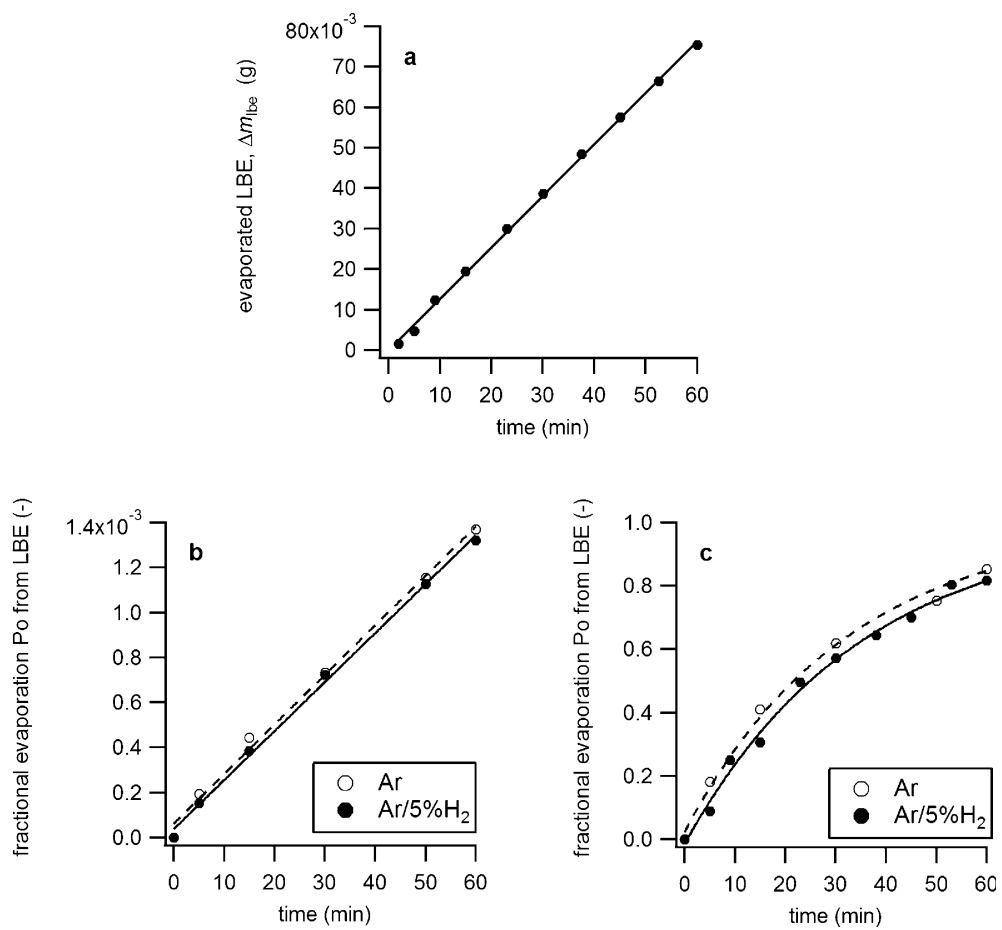

Fig. 2: Release of LBE and Po from LBE after different heating times in a flow of $100 \mathrm{~mL} / \mathrm{min}$ carrier gas. (a) Evaporated mass of LBE at $1000{ }^{\circ} \mathrm{C}$ in $\mathrm{Ar} / 5 \% \mathrm{H}_{2}$. (b) fractional release of Po from LBE at $600{ }^{\circ} \mathrm{C}$ in $\mathrm{Ar} / 5 \% \mathrm{H}_{2}$ and pure Ar and (c) fractional release of Po from LBE at $1000{ }^{\circ} \mathrm{C}$ in $\mathrm{Ar} / 5 \% \mathrm{H}_{2}$ and pure Ar. Solid and dashed lines: model fits for $\mathrm{Ar} / 5 \% \mathrm{H}_{2}$ and Ar data, respectively. Errors on the Po data at 1000 and $600{ }^{\circ} \mathrm{C}$ are approximately $10 \%$ and $1 \%$, respectively.

\subsection{Polonium diffusion in LBE and its effect on evaporation}

In case of evaporation of solute from a less volatile solvent, such as Po from LBE, depletion of the solute near the evaporation surface may occur due to limited diffusive transport of polonium in the bulk of the sample to the surface to supplement the evaporated solute. To evaluate how and to what extent diffusion limitations in the LBE affect polonium release in our experiments, we calculated the evolution of polonium concentration at different positions in an LBE sample during evaporation.

For this purpose the LBE sample was modeled as an isothermal slab-shape volume with dimensions $(3 \times 3 \times$ $20 \mathrm{~mm}^{3}$ ). Only the $3 \times 20 \mathrm{~mm}^{2}$ top surface of the volume was open for polonium exchange. The other surfaces were set closed for Po permeation and inert for adsorption of Po. This model is an approximation for the quartz boat in which the LBE sample was loaded. Within this model geometry the diffusion-advection equation was solved using the ANSYS software. A boundary condition was adopted which assumes that at the open surface, the polonium flux perpendicular to the sample surface due to diffusion equals the evaporation flux [26]:

$$
-\left.D_{\text {Po(lbe) }} \frac{\mathrm{d} C_{\text {Po(lbe) }}}{\mathrm{d} z}\right|_{\mathrm{s}}=\beta C_{\mathrm{Po}(\mathrm{lbe}), \mathrm{s}}
$$

where $D_{\text {Po(lbe) }}$ is the diffusion coefficient of Po in LBE $\left[\mathrm{m}^{2} \mathrm{~s}^{-1}\right], C_{\mathrm{Po}(\mathrm{lbe}), \mathrm{s}}$, is the Po concentration at the LBE surface, $\mathrm{d} C_{\mathrm{Po}(\mathrm{lbe})} /\left.\mathrm{d} z\right|_{\mathrm{s}}$ is the Po concentration gradient at the top surface and the factor $\beta\left[\mathrm{m} \mathrm{s}^{-1}\right]$ is the evaporation rate constant given by

$$
\beta=\frac{\dot{V} K_{\text {Po(lbe) }}}{R T_{0} A \rho_{\text {lbe }}}
$$

where $\rho_{\text {lbe }}\left[\mathrm{mol} \mathrm{m}^{-3}\right]$ is the molar density of LBE [6]. This expression is deduced from Equation (4) and likewise assumes saturated conditions and advective transport of polonium vapors.

To our knowledge, experimental values for the diffusion coefficient of Po in liquid LBE or its pure constituents $\mathrm{Pb}$ and $\mathrm{Bi}$ do not exist. The diffusion coefficient was therefore estimated following the method of Roy and Chhabra [27], developed for the prediction of solute diffusion coefficients in molten metals. The method considers that solute diffusion coefficients depend only on the atomic size of solute and solvent, thereby neglecting interactions. Despite this approximation, predictions of solute 
diffusion coefficients were in reasonable agreement with experimental values for a variety of solute/liquid metal solvent systems over wide ranges of temperature [27]. This supports the use of the model for the Po/LBE system. We estimated values of $D_{\mathrm{Po}(\mathrm{lbe})}=1.1 \times 10^{-8} \mathrm{~m}^{2} \mathrm{~s}^{-1}$ and $1.8 \times 10^{-8} \mathrm{~m}^{2} \mathrm{~s}^{-1}$ at $600{ }^{\circ} \mathrm{C}$ and $1000{ }^{\circ} \mathrm{C}$, respectively (see supplementary information for details).

With these estimated diffusion coefficients we calculated the concentration distribution of Po in the LBE model volume during a one-hour evaporation experiment at 600 and $1000{ }^{\circ} \mathrm{C}$. In Figure 3, two curves are plotted. One is the polonium concentration averaged over the whole volume of the model volume. The other curve is the polonium concentration averaged only over the top layer at the free surface. The thickness of this top layer is about $400 \mu \mathrm{m}$, as determined by the mesh resolution of the simulation. For comparison, average concentration data derived from the release data of Figure 2 are also shown.

At $600{ }^{\circ} \mathrm{C}$, curves for the volume and free surface average concentrations coincided, indicating that polonium depletion at the free surface was negligible (Figure 3). This is because the evaporation rate term at $600{ }^{\circ} \mathrm{C}$ is much smaller than the diffusive transport term. On the other hand at $1000{ }^{\circ} \mathrm{C}$, after a short transient, the free surface average concentration was about $8 \%$ smaller than the volume average concentration (Figure 3).

This calculation exercise suggests that the influence of diffusion limitation in the LBE on polonium evaporation is rather limited. The $8 \%$ difference at $1000{ }^{\circ} \mathrm{C}$ will cause underestimation of the Henry constant for Po in LBE by the same amount. Currently, however, this difference is within the range of the precision of our evaporation data (data markers in Figure 3) and derived Henry constants. With

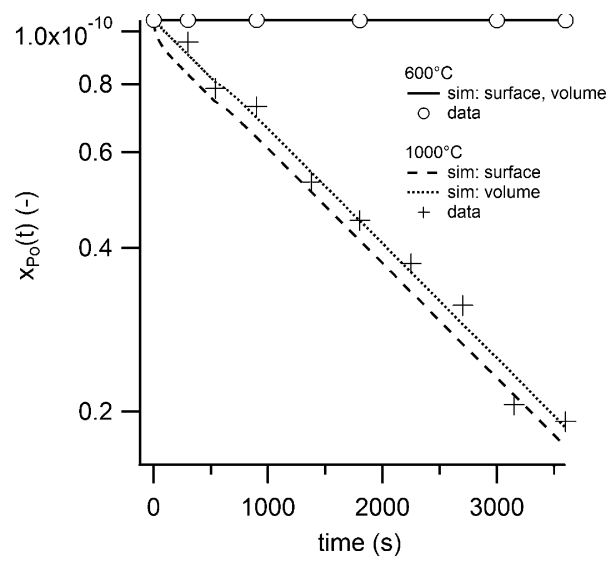

Fig. 3: (lines) Evolution of calculated volume and free surface average polonium concentrations during one-hour transpiration evaporation experiments at 600 and $1000^{\circ} \mathrm{C}$. (markers) Experimental average polonium concentrations. more precise evaporation measurements it should in principle be possible to detect diffusion limitations through the transient at the start of time-dependent evaporation experiments.

It is further noted that the calculation of polonium depletion thus far neglects mixing by convection, driven by temperature gradients in the liquid LBE sample. Convection of course tends to homogenize the sample and will result in a reduction of surface depletion. Temperature gradients in the sample are probably small because of the high thermal conductivity of LBE. Nevertheless even small temperature differences cause mixing as suggested by calculations in which we took into account natural convection driven by the top free surface at $999^{\circ} \mathrm{C}$ and the rest of the sample at $1000^{\circ} \mathrm{C}$. In that case, the difference between volume and free surface average concentrations was only about $4 \%$ (see supplementary information).

\subsection{Henry constants for Po(lbe) between 600 and $1000^{\circ} \mathrm{C}$}

In the previous paragraphs, we have shown that at 600 and $1000{ }^{\circ} \mathrm{C}$ in $\mathrm{Ar} / 5 \% \mathrm{H}_{2}$, polonium evaporates from $\mathrm{LBE}$ conform to the model predictions. It is then logical to assume that the model also holds at intermediate temperatures.

In Figure 4, two sets of data are plotted. Data between 700 and $1000{ }^{\circ} \mathrm{C}$ (open circles in Figure 4) were published previously [7] and were determined by measuring the dif-

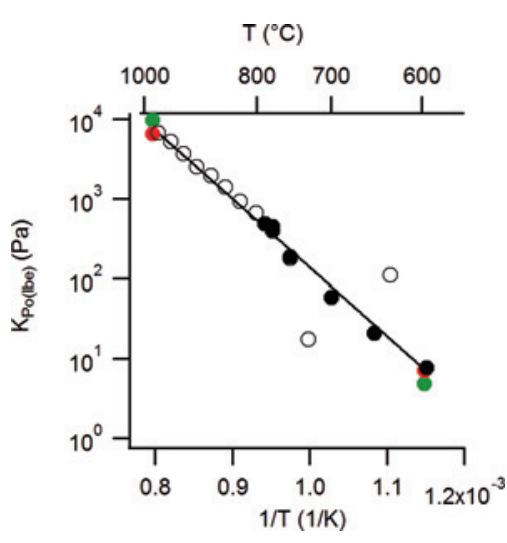

Fig. 4: Henry constants of Po/LBE at different temperatures in $\mathrm{Ar} / 5 \% \mathrm{H}_{2}$ at $x_{\mathrm{Po}(\mathrm{lbe})}=1 \times 10^{-10}$. (Black filled markers) data obtained from one-hour experiments at $100 \mathrm{~mL} / \mathrm{min}$, (green markers) data derived from time-dependent experiments and (red markers) derived from flow rate-dependent experiments. (Open circles) data from Ref. [7]. (Solid line) correlation derived in the present work, Eq. (10). Average error on the data: $10 \%\left(T>800^{\circ} \mathrm{C}\right)$ and $1 \%$ $\left(T<800^{\circ} \mathrm{C}\right)$. 
ference in polonium activity in the LBE sample before and after an evaporation experiment. The large scatter of this data set at temperatures around $700{ }^{\circ} \mathrm{C}$ reveals that this method is limited to temperatures above $800^{\circ} \mathrm{C}$. Data between 600 and $800^{\circ} \mathrm{C}$ (filled black circles) were obtained by directly measuring the evaporated polonium by the method developed by Rizzi et al. [8]. Clearly, this method allows measuring polonium evaporation at much lower temperatures. The current data further show (i) that both methods yield the same result and (ii) that the polonium data in the entire temperature range $600-1000{ }^{\circ} \mathrm{C}$ can be described using a single correlation for the temperature dependence of the Henry constant:

$$
\log K_{\mathrm{Po}(\mathrm{lbe})}=10.8 \pm 0.7-\frac{8606 \pm 726}{T}
$$

This correlation, which was obtained by fitting the full temperature range, is within experimental error identical to our previously published correlation which was based on the high temperature data only [7].

Besides the single-point temperature data, the Henry constants obtained from the flow rate and time-dependent experiments were also included in Figure 4. These data and the set from the temperature-dependent tests were in fairly good agreement.

\section{Conclusions}

The use of the transpiration method for investigating polonium evaporation from liquid lead bismuth eutectic was explored. By a systematic study of polonium release from LBE at different carrier gas flow rates and at different evaporation times, values of the equilibrium partial pressure of polonium above LBE and of the maximal evaporation rate of polonium into gas at atmospheric pressure were determined between 600 and $1000{ }^{\circ} \mathrm{C}$ in $\mathrm{Ar} / 5 \% \mathrm{H}_{2}$ and $\mathrm{Ar}$. These experiments showed that polonium evaporation can be described by a simple model which assumes that Henry's law is valid and that diffusion limitations in the liquid are not limiting the evaporation rate. Within the experimental boundary conditions of the present study, this model can be used for predictions of polonium release in safety studies for LBE based nuclear installations.

Acknowledgement: This work is supported by the European Commission through the FP7 project SEARCH (Safe ExploitAtion Related Chemistry for HLM reactors, project no. 295736) and by the Belgian government through the MYRRHA project. The technical assistance of Bart Van de Pol and Stefan Huysmans is greatly appreciated.
J.Martens acknowledges the Flemish Government for longterm structural funding (Methusalem). The authors acknowledge many helpful discussions with Stephan Heinitz and Emilio Andrea Maugeri (PSI, Villigen).

\section{References}

1. Andersson, J., Skagius, K., Winberg, A., Lindborg, T., Ström, A.: Site-descriptive modelling for a final repository for spent nuclear fuel in Sweden. Environ. Earth Sci. 69, 1045 (2013).

2. Ström, A., Andersson, J., Skagius, K., Winberg, A.: Site descriptive modelling during characterization for a geological repository for nuclear waste in Sweden. Appl. Geochem. 23, 1747 (2008).

3. Pirlet, V., Van Iseghem, P., Dierckx, A., Desreux, J-F.: The investigation of the neptunium complexes formed upon interaction of high level waste glass and Boom Clay media. J. Alloy. Compd. 271-273, 267 (1998).

4. Aït Abderrahim, H., Baeten, P., De Bruyn, D.: In: Proceedings of Technology and Components of Accelerator-driven Systems Workshop, March 15-17, 2010, Karlsruhe, Germany, pp. 33-42.

5. De Bruyn, D., Aït Abderrahim, H., Baeten, P., Fernandez, R.: MYRRHA, the Multi-purpose Hybrid Research Reactor for Hightech Applications. In: Proceedings of ICAPP 2011, May 2-5, 2011, Nice, France, Paper 11140.

6. OECD, Handbook on Lead-bismuth Eutectic Alloy and Lead Properties, Materials Compatibility, Thermal-hydraulics and Technologies. Nuclear Energy Agency, Organisation for Economic Co-operation and Development (2007) ISBN: 978-9264-99002-9. http://www.oecd-nea.org/science/reports/2007/ nea6195-handbook.html.

7. Gonzalez Prieto, B., Van den Bosch, J., Martens, J. A., Neuhausen, J., Aerts, A.: Equilibrium evaporation of trace polonium from liquid lead-bismuth eutectic at high temperature. J. Nucl. Mater. doi: http://dx.doi.org/10.1016/j.jnucmat.2013.06.037.

8. Rizzi, M., Neuhausen, J., Eichler, R., Türler, A., Melo Mendonça, T., Stora, T., Gonzalez Prieto, B., Aerts, A., Schumann, D.: Polonium evaporation from dilute liquid metal solutions. J. Nucl. Mater. doi: http://dx.doi.org/10.1016/j.jnucmat. 2014.01.047.

9. Aerts, A., Danaci, S., Gonzalez Prieto, B., Van den Bosch, J., Neuhausen, J.: Evaporation of mercury impurity from liquid lead-bismuth eutectic. J. Nucl. Mater., doi: http://dx.doi.org/ 10.1016/j.jnucmat.2014.02.013.

10. Gonzalez Prieto, B., Lim, J., Mariën, A., Rosseel, K., Martens, J. A., Van den Bosch, J., Neuhausen, J., Aerts, A.: Non-uniform polonium distribution in lead-bismuth eutectic revealed by evaporation experiments. J. Radioanal. Nucl. Ch. doi: http://dx.doi.org/10.1007/s10967-014-3264-1.

11. Rijpstra, K., Van Yperen-De Deyne, A., Neuhausen, J., Van Speybroeck, V., Cottenier, S.: Solution enthalpy of Po and Te in solid lead-bismuth eutectic. J. Nucl. Mater. doi: http://dx.doi.org/ 10.1016/j.jnucmat.2013.07.004.

12. Neuhausen, J., Köster, U., Eichler, B.: Investigation of evaporation characteristics of polonium and its lighter homologues selenium and tellurium from liquid $\mathrm{Pb}$-Bi-eutecticum. Radiochim. Acta 92, 917 (2004). 
13. Ohno, S., Kurata, Y., Miyahara, S., Katsura, R., Yoshida, S.: Equilibrium Evaporation Behavior of Polonium and Its Homologue Tellurium in Liquid Lead-Bismuth Eutectic. J. Nucl. Sci. Technol. 43, 1359 (2006).

14. Dharwadkar, S. R., Kerkar, A. S., Samant, M. S.: A microthermogravimetric system for the measurement of vapour pressure by a transpiration method. Thermochim. Acta 217, 175 (1993).

15. Merten, U., Bell, W. E.: The transpiration method. In: J. L. Margrave (Ed.), The Characterization of High-temperature Vapors, Wiley, New York 1967, p. 91-114.

16. Alcock, C. B., Hooper, G. W.: Measurement of vapor pressures at high temperatures by the transpiration method, In: G. Pierre (Ed.), Physical Chemistry of Process Metallurgy. Part 1, Interscience Publ., 1959, p. 325-340.

17. Ohno, S., Miyahara, S., Kurata, Y.: Experimental Investigation of Lead-Bismuth Evaporation Behavior. J. Nucl. Sci. Technol. 42, 593 (2005).

18. Hofmeister, H. K., Haeseler, R. v., Glemser, O.: Zum Einfluß der Strömungsgeschwindigkeit auf die Ermittlung von Gleichgewichtsdampfdrucken mit der Mitführungsmethode. Zeitschrift für Elektrochemie. 4, 513 (1960).

19. Stanislowski, M., Wessel, E., Markus, T., Singheiser, L.: Chromium vaporization from High-Temperature Alloys: I.
Chromia-Forming Steels and the Influence of Outer Oxide Layers, J. Electrochem. Soc. 154, A295-A306 (2007).

20. Holyst, R., Litniewski, M.: Evaporation into vacuum: Mass flux from momentum flux and the Hertz-Knudsen relation revisited. J. Chem. Phys. 130, 074707 (2009).

21. Pound, G. M.: Selected Values of Evaporation and Condensation Coefficients for Simple Substances. J. Phys. Chem. 1, 135 (1972).

22. L'vov, B. V.: The physical approach to the interpretation of the kinetics and mechanisms of thermal decomposition of solids: the state of the art. Thermochim. Acta 373, 97 (2001).

23. Feuerstein, H., Gräbner, H., Oschinski, J., Horn, S., Bender, S.: Evaporation of lead and lithium from molten Pb-17Li-Transport of aerosols. Fusion. Eng. Des. 17, 203 (1991).

24. Feuerstein, H. Oschinski, J., Horn, S.: Behavior of Po-210 in molten Pb-17Li. J. Nucl. Mater. 191-194, 288 (1992).

25. Lim, J., Mariën, A., Rosseel, K., Aerts, A., Van den Bosch, J.: Accuracy of potentiometric oxygen sensors with $\mathrm{Bi} / \mathrm{Bi}_{2} \mathrm{O}_{3}$ reference electrode for use in liquid LBE. J. Nucl. Mater. 429, 270 (2012).

26. Crank, J.: The mathematics of diffusion. Clarendon Press, Oxford 1970.

27. Roy, A. K., Chhabra, R. P.: Prediction of Solute Diffusion Coefficients in Liquid Metals. Metall. Trans. A 19A, 273 (1988). 